To be published in Effects of Radiation on Materials, 19th International Symposium, ASTM STP 1366, held in Seattle, Washington, June 16-18, 1998

\title{
Irradiation, Annealing, and Reirradiation Effects on American and Russian Reactor Pressure Vessel Steels
}

\author{
M. A. Sokolov, ${ }^{1}$ A. A. Chernobaeva, ${ }^{2}$ R. K. Nanstad, ${ }^{1}$ \\ Yu. A. Nikolaev, ${ }^{2}$ and Yu. N. Korolev ${ }^{2}$ \\ Metals and Ceramics Division \\ OAK RIDGE NATIONAL LABORATORY \\ P.O. Box 2008 \\ Oak Ridge, TN 37831-6151
}

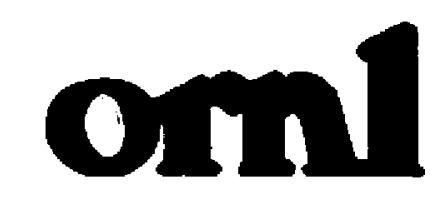

${ }^{1}$ Metals and Ceramics Division, Oak Ridge National Laboratory, P.O. Box 2008, Oak Ridge, TN 37831-6151, managed by Lockheed Martin Energy Research Corporation under contract DE-AC05-960R22464 for the U.S. Department of Energy.

${ }^{2}$ Russian Research Center-Kurchatov Institute, 123182 Moscow, Russia.

\footnotetext{
The submitied manuscript has been authored by a contracior of the U.S. Government under contract No. DE-AC05-960R22464. Accordingly, the U.S. Government retains a nonexclusive, royalty-free license to publish or reproduce the published form of this contribution, or allow others to do so, for U.S. Government purposes.
} 
M. A. Sokolov, ${ }^{1}$ A. A. Chernobaeva, ${ }^{2}$, R. K. Nanstad, ${ }^{1}$ Yu. A. Nikolaev, ${ }^{2}$ and Yu. N. Korolev ${ }^{2}$

Irradiation, Annealing, and Reirradiation Effects on American and Russian Reactor Pressure Vessel Steels

Reference: Sokolov, M. A., Chernobaeva, A. A., Nanstad, R. K., Nikolaev, Y. A., and Korolev, Y. N., "Irradiation, Annealing, and Reirradiation Effects on American and Russian Reactor Pressure Vessel Steels," Effects of Radiation on Materials, 19th International Symposium, ASTM STP 1366, M. L. Hamilton, A. S. Kumar, S. T. Rosinski, and M. L. Grossbeck, Eds., American Society for Testing and Materials, West Conshohocken, Pennsylvania, 1999.

Abstract: One of the options to mitigate the effects of irradiation on reactor pressure vessels (RPVs) is to thermally anneal them to restore the toughness properties that have been degraded by neutron irradiation. Even though a postirradiation anneal may be deemed successful, a critical aspect of continued RPV operation is the rate of embrittlement upon reirradiation. There are insufficient data available to allow for verification of available models of reirradiation embrittlement or for the development of a reliable predictive methodology. This is especially true in the case of fracture toughness data. Under the U.S.-Russia Joint Coordinating Committee for Civilian Nuclear Reactor Safety (JCCCNRS), Working Group 3 on Radiation Embrittlement, Structural Integrity, and Life Extension of Reactor Vessels and Supports agreed to conduct a comparative study of annealing and reirradiation effects on RPV steels. The Working Group agreed that each side would irradiate, anneal, reirradiate (if feasible), and test two materials of the other. Charpy V-notch (CVN) and tensile specimens were included. Oak Ridge National Laboratory (ORNL) conducted such a program (irradiation and annealing, including static fracture toughness) with two weld metals representative of VVER-440 and VVER-1000 RPVs, while the Russian Research Center-Kurchatov Institute (RRC-KI) conducted a program (irradiation, annealing, reirradiation, and reannealing) with Heavy-Section Steel Technology (HSST) Program Plate 02 and Heavy-Section Steel Irradiation (HSSI) Program Weld $73 \mathrm{~W}$. The results for each material from each laboratory are compared with those from the other laboratory. The ORNL experiments with the VVER welds included irradiation to about $1 \times 10^{19} \mathrm{n} / \mathrm{cm}^{2}(>1 \mathrm{MeV})$, while the RRC-KI experiments with the U.S. materials included irradiations from about 2 to $18 \times 10^{19} \mathrm{n} / \mathrm{cm}^{2}(>1 \mathrm{MeV})$. In both cases, irradiations were conducted at $\sim 290^{\circ} \mathrm{C}$ and annealing treatments were

${ }^{1}$ Oak Ridge National Laboratory, P.O. Box 2008, Oak Ridge, TN 37831-6151.

${ }^{2}$ Russian Research Center-Kurchatov Institute, 123182 Moscow, Russia. 
conducted at $\sim 454^{\circ} \mathrm{C}$. The ORNL and RRC-KI experiments have shown generally good agreement for both the Russian and U.S. steels. While recoveries of the Charpy 41-J transition temperatures were substantial in all cases, significantly less recovery of the lateral expansion and shear fracture in some cases (no recovery in one case) deserves further attention. The RRC-KI results for the U.S. steels showed reirradiation embrittlement rates which are conservative relative to the lateral shift prediction based on Charpy impact energy.

Keywords: Charpy, embrittlement, annealing, reirradiation, reactor pressure vessel

\section{Introduction}

One of the options to mitigate the effects of irradiation on RPVs is to thermally anneal them to restore the toughness properties that have been degraded by neutron irradiation. Even though a postirradiation anneal may be deemed successful, a critical aspect of continued RPV operation is the rate of embrittlement upon reirradiation. There are insufficient data available to allow for verification of available models of reirradiation embrittlement or for the development of a reliable predictive methodology. This is especiaily true in the case of fracture toughness data. Under the U.S.-Russia JCCCNRS, Working Group 3 on Radiation Embrittlement, Structural Integrity, and Life Extension of Reactor Vessels and Supports agreed to conduct a comparative study of annealing and reirradiation effects on RPV steels. The Working Group agreed that each side would irradiate, anneal, reirradiate (if feasible), and test two materials of the other. CVN and tensile specimens have been included. ORNL conducted such a program (irradiation and annealing) with two weld metals representative of VVER-440 and VVER-1000 RPVs including static three-point bend tests of precracked CVN (PCVN) specimens, while the RRC-KI conducted a program (irradiation, annealing, reirradiation, and reannealing) with HSST Plate 02 and HSSI Weld $73 \mathrm{~W}$. The results for each material from each laboratory are compared with those from the other laboratory.

\section{Materials}

Three welds and one base metal were characterized in the present study. The chemical compositions and mechanical properties in the unirradiated condition are listed in Tables 1 and 2, respectively. The base metal was American Society for Testing and Materials (ASTM) A 533 grade B class 1 plate, designated HSST Plate 02, portions of which have been used in many investigations around the world. The plate was edgequenched in water after austenitizing at $871^{\circ} \mathrm{C}$, then tempered at $663^{\circ} \mathrm{C}$ for $4 \mathrm{~h}$ and furnace cooled. The final stress relief was performed at $621^{\circ} \mathrm{C}$ for $40 \mathrm{~h}$ [1]. One of the welds, designated HSSI Weld $73 \mathrm{~W}$, was specially produced for the HSSI Program by Combustion Engineering, Inc., using the submerged-arc process with Linde 0124 flux. The weld was postweld heat treated at $607^{\circ} \mathrm{C}$ for $40 \mathrm{~h}[2,3]$. The weld is known to be a high-copper (radiation-sensitive) weld.

The two other welds were specially produced by the Izhora Plant to exemplify radiation-sensitive welds of two Russian-made commercial reactors, VVER-440 and 
VVER-1000. Both welds were made using the submerged-arc process. The VVER-440 weld, designated Weld 502, was made by weld wire Sv-10KhMFT with flux AN-42M. It is characterized by low nickel and high phosphorus contents $(<0.20$ and $\sim 0.030 \%$, respectively), typical for older VVER-440 vessel welds. The weld was heat treated at $675^{\circ} \mathrm{C}$ for $34 \mathrm{~h}$. The VVER-1000 weld, designated Weld 260 , was made by weld wire Sv-12Kh2N2MAA with flux FTs-16. The VVER-1000 materials, including the Weld 260, have low copper and phosphorus contents ( $<0.10$ and $<0.012 \%$, respectively). Weld 260 is also characterized by high nickel content (1.64\%), which is typical for old VVER-1000 vessel welds. The weld was heat treated at $620^{\circ} \mathrm{C}$ for $17.5 \mathrm{~h}$, furnace cooled, then heat treated at $640^{\circ} \mathrm{C}$ for $9.5 \mathrm{~h}$.

\section{Test Procedures}

The test program concentrated on comparison of changes in Charpy impact properties due to irradiation and annealing. RRC-KI performed tests using the RKP-300 pendulum-type Amsler impact testing machine. A ISO-type instrumented striker with a $2-\mathrm{mm}$ radius was used for tests at RRC-KI. Charpy tests at ORNL were conducted in accordance with ASTM Standard E-23, using an 8-mm radius instrumented striker.

Additionally, ORNL performed a limited number of tensile and static fracture toughness tests. Round tensile specimens with a gage section $4.52 \mathrm{~mm}$ in diameter and $31.75 \mathrm{~mm}$ in length were tested, while compact and PCVN specimens were used for fracture toughness characterization of irradiated and annealed material.

\section{Analysis of Charpy Data}

Charpy absorbed energy data of the four materials studied in the unirradiated condition are presented in Figure 1(a) through (d). Charpy data from both laboratories are in good agreement, despite the difference in the strikers used.

ORNL has been involved in a number of cross-comparison Charpy testing exercises with 2- and 8-mm radii instrumented strikers (including one with RRC-KI) and summarized the comparison results [4]. The overall results have showed generally good agreement in absorbed energy measurements by the two strikers in the energy range below $200 \mathrm{~J}$. The current data are consistent with that observation. Therefore, the unirradiated data from the two laboratories for each material in this study were combined and these results [shown in Fig. 1(a) through (d)] were used as the reference Charpy data set for each material. Charpy data for each material/condition were fit to the hyperbolic tangent function:

$$
E=\frac{U S E+L S E}{2}+\frac{U S E-L S E}{2} \times \tanh \left(\frac{T-T_{T M}}{C}\right)
$$

where $E$ is absorbed energy, lateral expansion, or shear fracture; $U S$ and $L S$ are upperand lower-shelf values of $E ; T_{M T}$ is the temperature at the middle of the transition range; and $C$ is the slope of the curve in the transition range at $T_{M T}$. Fitting was performed with 


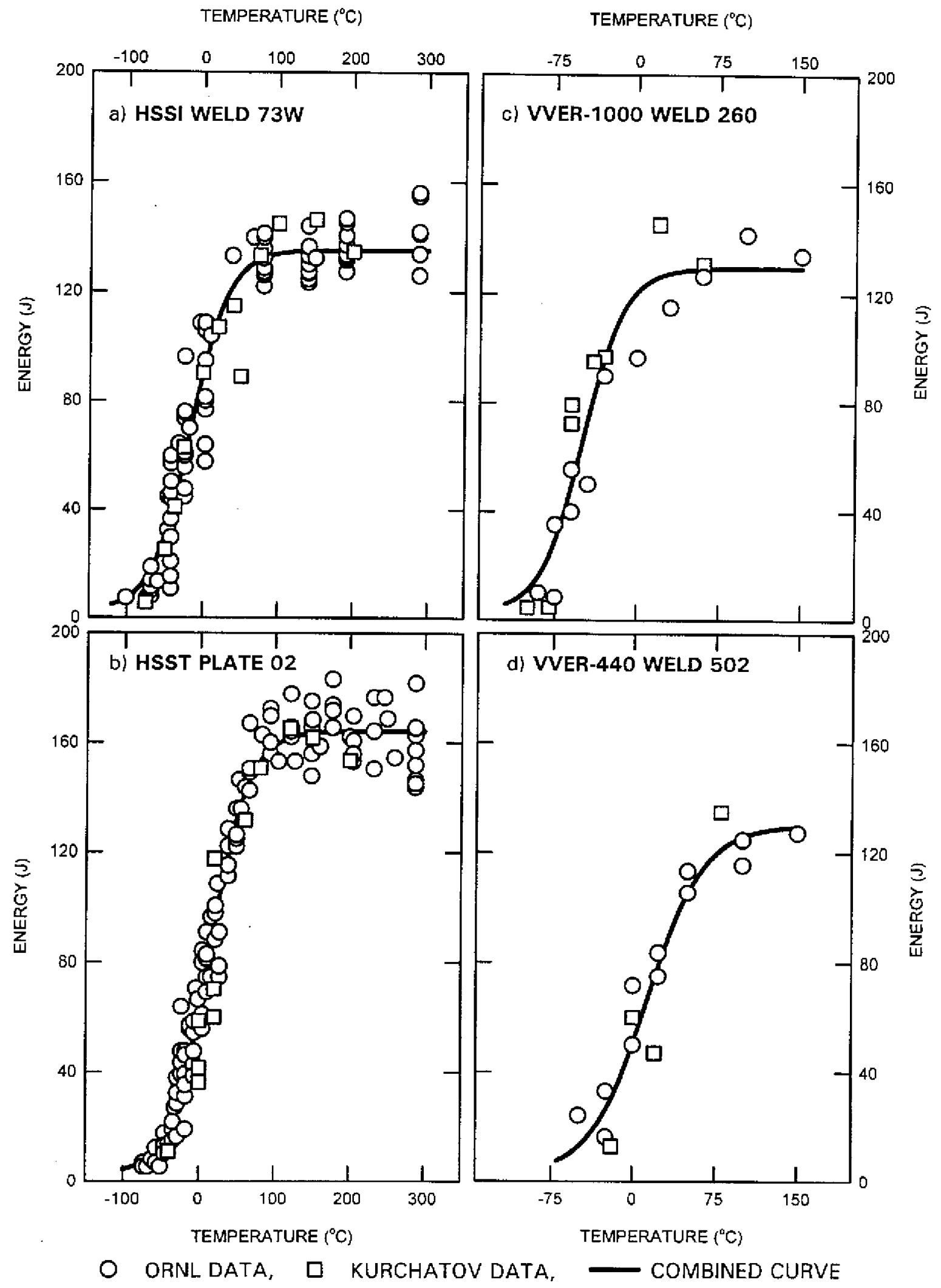

Fig. 1. Charpy data from materials studied in the unirradiated condition tested at ORNL and RRC-KI. Solid line is the best fit to combined data using a hyperbolic tangent function. 
LSE fixed at $2.7 \mathrm{~J}$ for energy, $0.061 \mathrm{~mm}$ for lateral expansion, and $0 \%$ for shear, respectively [2]. Additionally, the upper-shelf value for shear was fixed at $100 \%$.

The transition temperature is the main parameter derived from the Charpy tests. It defines a temperature which corresponds to a certain level of energy, lateral expansion, or shear. This level is accepted to be $0.9 \mathrm{~mm}$ for lateral expansion and $50 \%$ for shear according to the current practices in both countries. However, the radiation-induced transition temperature shift is measured at the level of $41 \mathrm{~J}$ in the U.S., while it is measured at $47 \mathrm{~J}$ in Russia. Indexing at 41 or $47 \mathrm{~J}$ reflects a difference of a historical practice rather than a technical one. The $41-\mathrm{J}$ level corresponds to $30 \mathrm{ft}-\mathrm{lb}$, while $47 \mathrm{~J}$ corresponds to $6 \mathrm{kgf} \cdot \mathrm{m} / \mathrm{cm}^{2}$, commonly used indices in the United States and Russia, respectively. But practically, they are from about the same neighborhood in the transition range for RPV materials. In order to provide data according to the relevant national practice, the shifts of transition temperature due to irradiation or annealing will be reported as measured at $47 \mathrm{~J}$ for Russian welds, and at $41 \mathrm{~J}$ for the U.S. steels, regardless of the test laboratory.

\section{Irradiation Conditions}

The ORNL experiments with the VVER welds included irradiation to about $1 \times 10^{19} \mathrm{n} / \mathrm{cm}^{2}(>1 \mathrm{MeV})$ in the University of Michigan Ford Reactor, while the RRC-KI experiments with the U.S. materials included irradiations from about 2 to $18 \times 10^{19} \mathrm{n} / \mathrm{cm}^{2}$ $(>1 \mathrm{MeV}$ ) in Unit 5 of the Novo-Voronezh Nuclear Power Plant (NVNPP-5), a VVER-1000 type reactor. In both cases, irradiations were conducted at $\sim 290^{\circ} \mathrm{C}$. Additionally, Charpy and tensile specimens of Weld 502 were irradiated by ORNL at $275^{\circ} \mathrm{C}$, a temperature which is closer to the operating temperature $\left(270^{\circ} \mathrm{C}\right)$ of VVER-440 reactor vessels.

Besides the differences between U.S. and Russian practices in indexing absorbed energy for determination of the transition temperature, there is also a difference in the measures of neutron fluence used. In the United States, neutron fluence for RPVs is measured for neutrons having energies greater than $1 \mathrm{MeV}$, while in Russia it is for neutrons having energies greater than $0.5 \mathrm{MeV}$. Thus, the values of neutron fluence for U.S. and Russian materials in this paper will be reported for neutrons with energies greater than 1.0 and $0.5 \mathrm{MeV}$, respectively, regardless of the source of irradiation. However, because the dosimetric procedures for each source were performed in the standard manner, estimates for adjustment must be determined. To determine the neutron irradiation exposure parameters, each country uses a neutron spectrum adjustment procedure that combines transport calculations of the neutron field and measurements using neutron monitors from irradiation capsules. The values of neutron fluence with $>0.5 \mathrm{MeV}$ for Russian welds irradiated by ORNL as well as the values of neutron fluence with $>1 \mathrm{MeV}$ for American steels irradiated by the RRC-KI given in this paper should be considered as the best currently available estimates. ORNL made this estimate by using a ratio, of flux of neutrons with $>0.5 \mathrm{MeV}$ to those with $>1 \mathrm{MeV}$, equal to 1.76 for the capsule irradiated in the Ford Reactor, while RRC-KI used a ratio of 2.11 for their capsules irradiated in NVNPP-5. 
Table 1 - Chemical Composition of Materials Used in the Annealing and Reirradiation Studies

\begin{tabular}{|l|l|c|c|c|c|c|c|c|c|}
\hline \multirow{2}{*}{\multicolumn{1}{|c|}{ Material }} & \multicolumn{10}{c|}{ Composition (wt \%) } \\
\cline { 2 - 11 } & $\mathrm{C}$ & $\mathrm{Mn}$ & $\mathrm{P}$ & $\mathrm{S}$ & $\mathrm{Cr}$ & $\mathrm{Ni}$ & $\mathrm{Mo}$ & $\mathrm{Cu}$ & $\mathrm{V}$ \\
\hline HSST Plate 02 & 0.23 & 1.55 & 0.009 & 0.014 & 0.04 & 0.67 & 0.53 & 0.14 & 0.003 \\
HSSI Weld 73W & 0.098 & 1.56 & 0.005 & 0.005 & 0.25 & 0.60 & 0.58 & 0.31 & 0.003 \\
Weld 502 (VVER-440) & 0.03 & 1.16 & 0.030 & 0.013 & 1.60 & 0.12 & 0.48 & 0.15 & 0.24 \\
Weld 260 (VVER-1000) & 0.08 & 0.85 & 0.009 & 0.015 & 1.83 & 1.64 & 0.61 & 0.07 & - \\
\hline
\end{tabular}

Table 2 - Mechanical Properties of Materials Studied in the Unirradiated Condition

\begin{tabular}{|l|c|c|c|c|c|c|c|}
\hline \multirow{2}{*}{ Material } & \multicolumn{3}{|c|}{ Transition temperature $\left({ }^{\circ} \mathrm{C}\right)$} & \multirow{2}{*}{$\begin{array}{c}\text { USE } \\
\text { (J) }\end{array}$} & \multicolumn{2}{c|}{$\begin{array}{c}\text { Room temperature } \\
\text { tensile strength (MPa) }\end{array}$} \\
\cline { 2 - 5 } \cline { 7 - 9 } & at 41 J & at 47 J & at $0.9 \mathrm{~mm}$ & at 50\% & & Yield & Ultimate \\
\hline Plate 02 & -14 & NA & -1 & 27 & 164 & 467 & 622 \\
Weld 73W & -39 & NA & -27 & -15 & 135 & 494 & 604 \\
Weld 502 (VVER-440) & NA & -3 & 2 & 20 & 130 & 437 & 546 \\
Weld 260 (VVER-1000) & NA & -62 & -51 & -39 & 130 & 490 & 583 \\
\hline
\end{tabular}

Table 3 - Fitting Coefficient (A) Compared with Chemistry Factor (CF) from RG 1.99 for U.S. Materials and Embritttlement Coefficient $\left(A_{1}\right)$ from CS-86 for Russian Welds

\begin{tabular}{|l|c|c|c|c|c|c|}
\hline \multirow{2}{*}{ Material } & \multicolumn{3}{|c|}{ Composition (wt \%) } & \multicolumn{3}{c|}{$\left({ }^{\circ} \mathrm{C}\right)$} \\
\cline { 2 - 7 } & $\mathrm{P}$ & $\mathrm{Cu}$ & $\mathrm{Ni}$ & $\mathrm{A}$ & $\mathrm{CF}$ & $\mathrm{A}_{\mathrm{F}}$ \\
\hline Plate 02 & 0.009 & 0.14 & 0.67 & 65.6 & 56 & $\mathrm{NA}$ \\
Weld 73W & 0.005 & 0.31 & 0.60 & 86.7 & 110 & $\mathrm{NA}$ \\
Weld 502 (VVER-440) & 0.030 & 0.15 & 0.12 & 16.6 & $\mathrm{NA}$ & 32.4 \\
Weld 260 (VVER-1000) & 0.009 & 0.07 & 1.64 & 22.0 & $\mathrm{NA}$ & 20 \\
\hline
\end{tabular}




\section{Irradiation and Annealing Results}

Results from the primary irradiation experiments with HSST Plate 02 and HSSI Weld $73 \mathrm{~W}$ performed by ORNL were previously published $[3,5,6]$. Fracture toughness characterization of these steels has been also performed in these studies. Recently, cleavage fracture toughness data $\left(\mathrm{K}_{\mathrm{Jc}}\right)$ for these steels were reevaluated using the master curve analysis procedure [7]. The procedure applies a statistical distribution function to characterize scatter of fracture toughness in the transition range and weakest-link theory to account for size effects, see Ref. [7] for details. It introduces the reference fracture toughness temperature, $\mathrm{T}_{100}$, as a temperature at which the median fracture toughness equals $100 \mathrm{MPa} \cdot \mathrm{m}^{1 / 2}$. The shift of $\mathrm{T}_{100}$ is used in the present work to characterize effects of irradiation and/or annealing on cleavage fracture toughness. In the present study, PCVN specimens of VVER-440 Weld 502 were tested in three-point bending by ORNL to provide fracture toughness characterization of this weld in the unirradiated, irradiated, and irradiated/annealed conditions.

Irradiation and annealing results are summarized in Fig. 2(a) through (d) for both the U.S. and Russian steels. The materials studied were irradiated to a wide range of neutron fluences. In general, the irradiation and annealing experiments conducted by RRC-KI and ORNL show reasonable agreement. Two different fitting functions were used to represent the embrittlement path (I) for the materials studied. For Plate 02 and Weld $73 \mathrm{~W}$ it is

$$
\Delta T T=A \cdot F^{(0.28-0.1 \log F)},
$$

where $\Delta T T$ is the shift of Charpy energy at $41 \mathrm{~J}$ or fracture toughness at $100 \mathrm{MPa} \cdot \mathrm{m}^{1 / 2}$; $F$ is neutron fluence in units of $10^{19} \mathrm{n} / \mathrm{cm}^{2}(>1 \mathrm{MeV})$; and $A$ is a fitting parameter. This fitting function has the same form and the same constants in the exponent as the one in U.S. Nuclear Regulatory Commission (NRC) Regulatory Guide 1.99 (RG 1.99), Revision 2 [8]. For VVER-440 and VVER-1000 welds it is

$$
\Delta T T=A \cdot F^{1 / 3}
$$

where $F$ is neutron fluence in units of $10^{18} \mathrm{n} / \mathrm{cm}^{2}(>0.5 \mathrm{MeV})$. This fitting function has the same form and the same constant in the exponent as the one in the Russian Standards (CS-86) [9].

The fitting parameters are compared with chemistry factors (CF) from RG 1.99 for Plate 02 and Weld $73 \mathrm{~W}$ and embrittlement coefficients $\left(A_{F}\right)$ from CS-86 for VVER-1000 Weld 260 in Table 3 . Weld 502 represents the materials for the older generation of VVER -440 reactors which operate at $270^{\circ} \mathrm{C}$ and $\mathrm{CS}-86$ provides the embrittlement coefficient calculation procedure for this irradiation temperature as well as for $250^{\circ} \mathrm{C}$, but not for an irradiation temperature of $290^{\circ} \mathrm{C}$. However, ORNL performed irradiation of this weld at $275^{\circ} \mathrm{C}$ in addition to irradiation at $290^{\circ} \mathrm{C}$. This allowed for a possibility to 

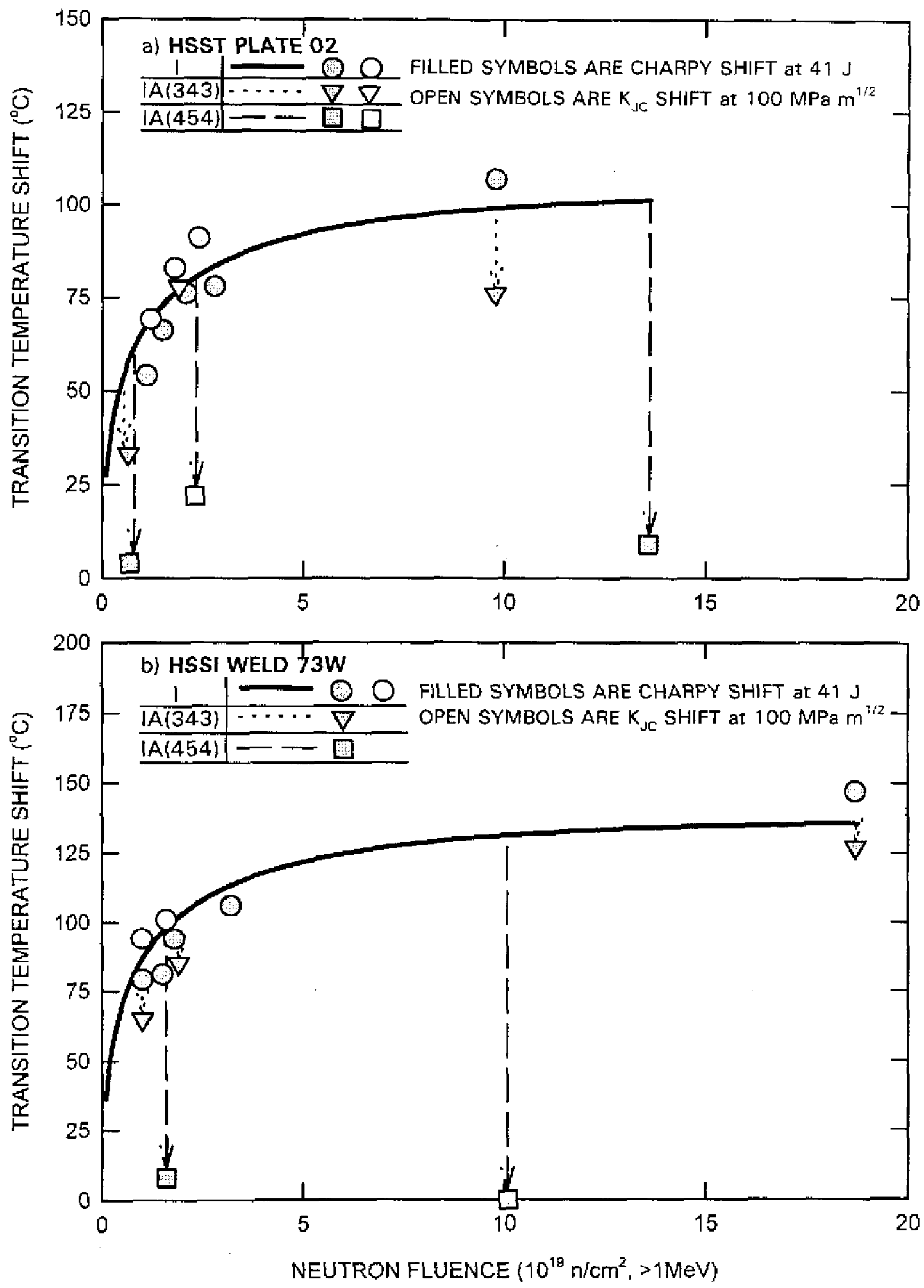

Fig. 2. Shift of the transition temperature due to irradiation and annealing.

(a) HSST Plate 02, (b) HSSI Weld 73 W. 

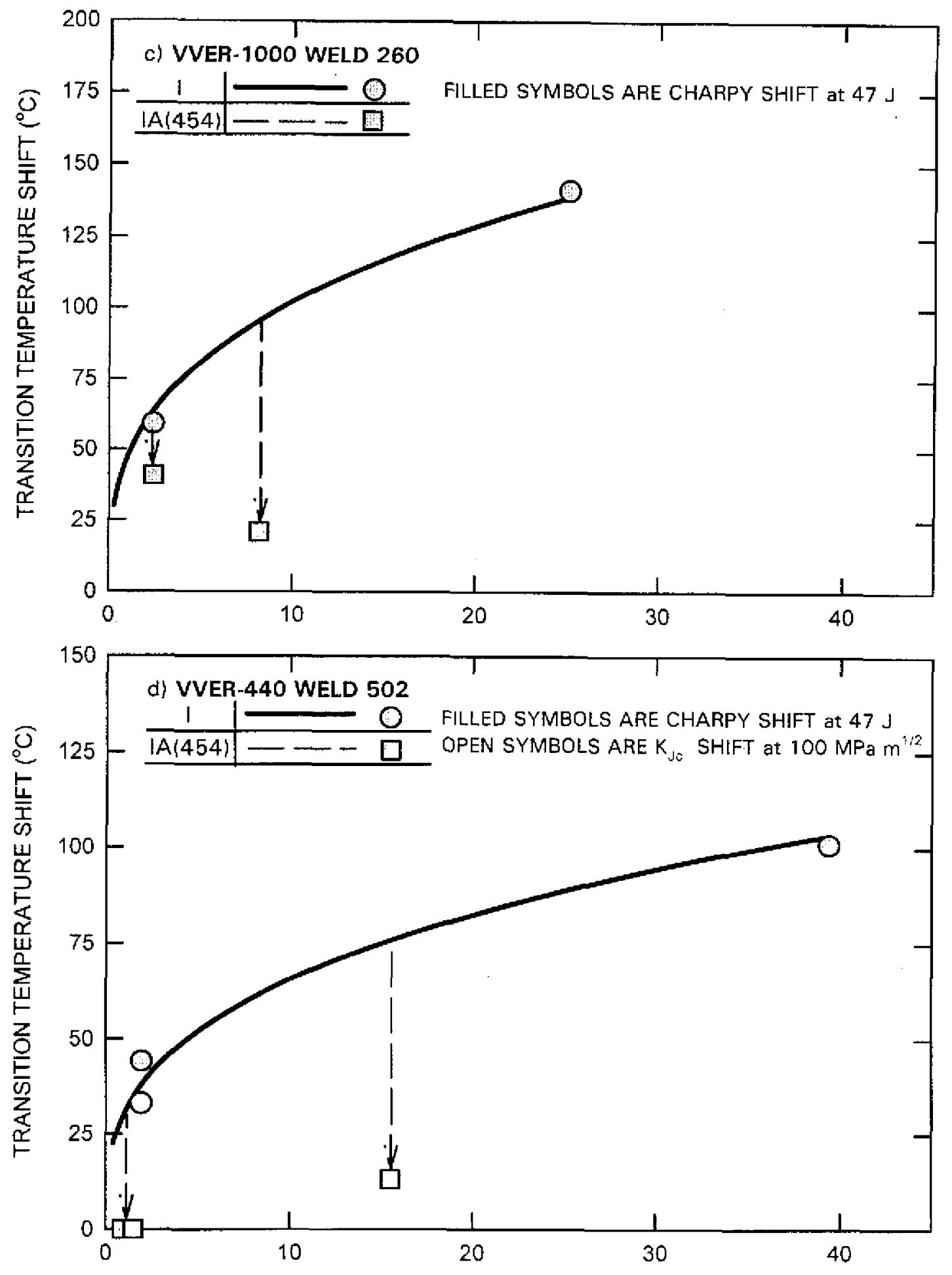

NEUTRON FLUENCE $\left(10^{19} \mathrm{n} / \mathrm{cm}^{2},>0.5 \mathrm{MeV}\right)$

Fig. 2. Shift of the transition temperature due to irradiation and annealing.

(c) VVER-1000 Weld 260, (d) VVER-440 Weld 502. 
compare $A_{\mathrm{F}}$ predicted from CS-86 to the one determined from the Charpy data irradiated at $275^{\circ} \mathrm{C}$. These values of $A_{F}$ for the Weld 502 are also presented in Table 3 . Figure 3 shows the Charpy energy data for Weld 502 irradiated at two temperatures.

The data in Table 3 show that the CS-86 provides a very conservative value of $A_{F}$ for the VVER-440 Weld 502 compared to the fitting coefficient from the present study. Contrary to that, however, the high-nickel VVER-1000 weld exhibited an embrittlement coefficient higher than that from the CS-86. That raises concerns regarding the ability of the current Russian practice to adequately predict the radiation embrittlement of highnickel welds in VVER-1000 reactor vessels. For HSST Plate 02 and HSSI Weld $73 \mathrm{~W}$, the fitting coefficients are within 2 standard deviations of the mean CF parameters from RG 1.99.

A significant difference in the experiments is that those conducted by RRC-KI involved much higher neutron fluences than those conducted by ORNL. These results are extremely important for Plate 02 and Weld $73 \mathrm{~W}$ in that they show neither material exhibits unexpected radiation sensitivity at very high fluences and, further, that both highly irradiated materials show nearly full recovery of Charpy toughness after annealing at $454^{\circ} \mathrm{C}$.

ORNL also performed tensile tests of VVER-440 and VVER-1000 welds in the irradiated and annealed conditions. Tensile properties of Plate 02 and Weld $73 \mathrm{~W}$ in the irradiated condition have been previously reported [2,5]. The radiation-induced changes in yield strength for the materials studied were compared to the shifts of Charpy transition temperature. The data are in very good agreement with the large Power Reactor Embrittlement Data. Base (PR-EDB) maintained at ORNL for the NRC (Fig. 4).

Two annealing temperatures were involved in the present study. Annealing temperature $343^{\circ} \mathrm{C}$ was applied to Plate 02 and Weld $73 \mathrm{~W}$ only, while all four materials were annealed at $454^{\circ} \mathrm{C}$. In general, annealing at $454^{\circ} \mathrm{C}$ provides more complete recovery of the transition temperature than that at $343^{\circ} \mathrm{C}$. The residual shift of transition temperature (the difference between transition temperatures of a material after annealing and in the unirradiated condition) increases with increase in neutron fluence for the $343^{\circ} \mathrm{C}$ annealing temperature.

It was noticed that fracture toughness shifts [Fig. 2(a) and (b)] are slightly higher than the Charpy shifts for Plate 02 and Weld $73 \mathrm{~W}$. Additionally, recovery of the fracture toughness shift seems to be less than the Charpy shift recovery at both annealing temperatures for Plate 02 . The difference is relatively small. Contrarily, fracture toughness shifts for VVER-440 Weld 502 were slightly less than Charpy shifts and full recovery after annealing at $454^{\circ} \mathrm{C}$ was observed for both transition temperatures. Observed differences between Charpy and fracture toughness shifts are within the scatter reported in Refs. [10,11].

According to the present data, the annealing temperature of $454^{\circ} \mathrm{C}$ is high enough to provide nearly complete recoveries of the transition temperatures even after irradiation to very high fluences. Moreover, RRC-KI has reirradiated some Charpy specimens of Plate 02 and Weld $73 \mathrm{~W}$ which were annealed at $454^{\circ} \mathrm{C}$ and then performed additional annealing of reirradiated specimens at $454^{\circ} \mathrm{C}$ (see the following section). Altogether, the data indicate very positive recovery of transition temperature after annealing at $454^{\circ} \mathrm{C}$ and that residual shift does not accumulate with neutron fluence or with cycling of irradiation 


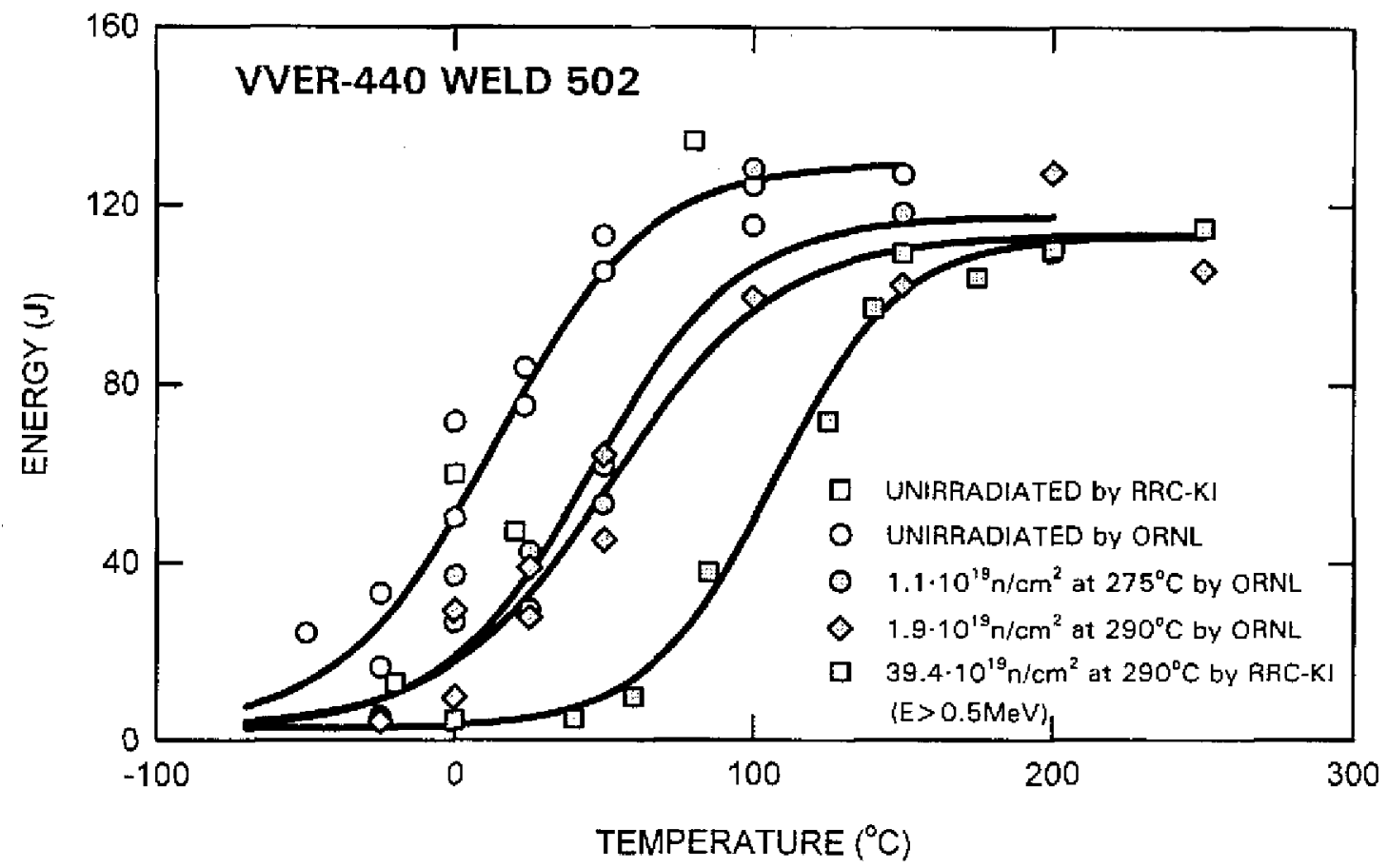

Fig. 3. ORNL and RRC-KI Charpy data of VVER-440 Weld 502 in the unirradiated condition and after irradiation at 275 and $290^{\circ} \mathrm{C}$.

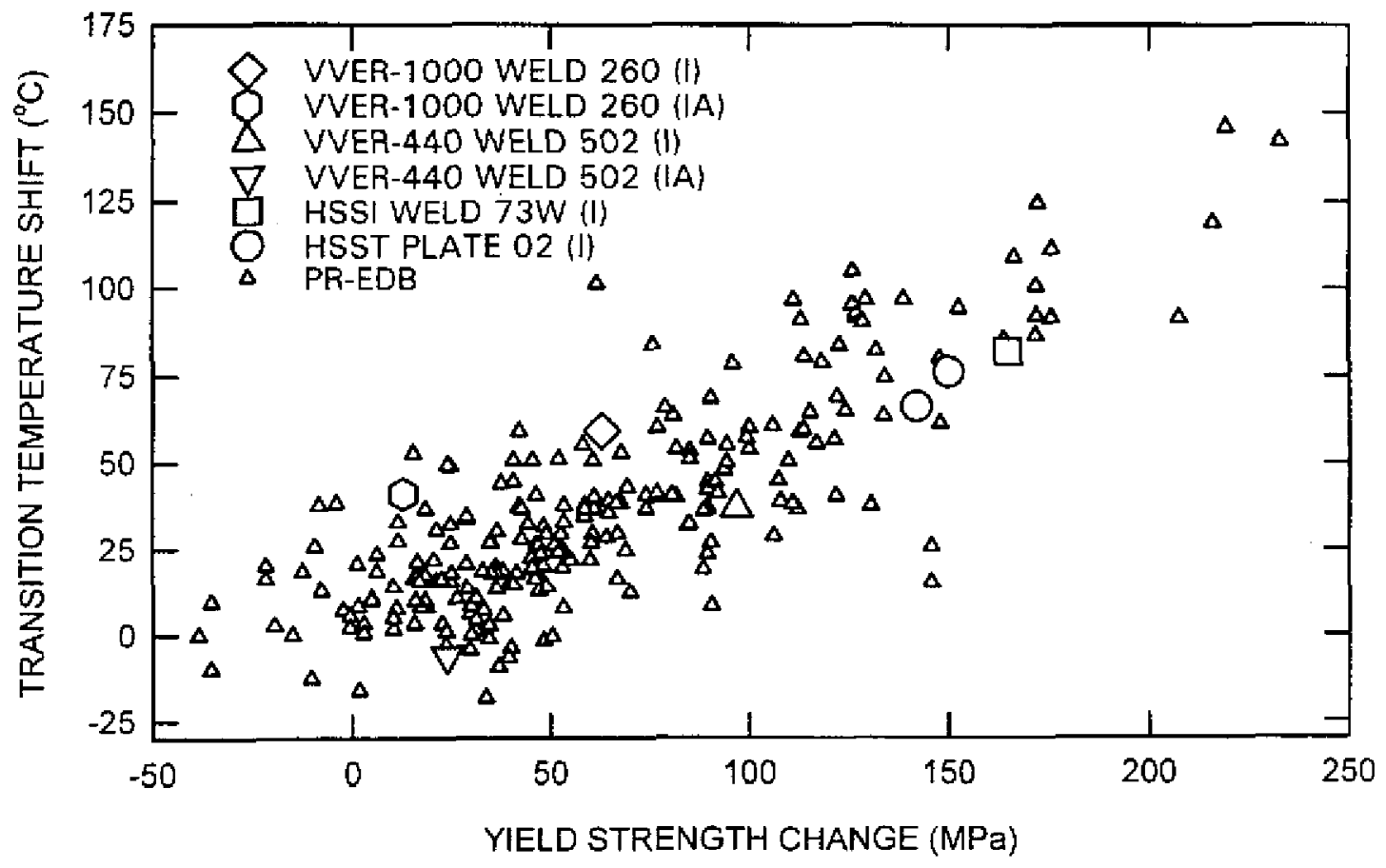

Fig. 4. Transition temperature shift versus change in yield strength for the materials studied by ORNL in comparison with PR-EDB data. 
and annealing at $454^{\circ} \mathrm{C}$. This observation is in a good agreement with earlier work on VVER-440 materials [12].

Recovery of the Charpy energy transition temperature was the primary objective in the present study. However, it was observed that other Charpy specimen measurements react differently on annealing at $454^{\circ} \mathrm{C}$. Figures 5 through 8 present absorbed energy, lateral expansion, and percent shear data of specimens tested after annealing at $454^{\circ} \mathrm{C}$ for Plate 02 and Welds $73 \mathrm{~W}, 502$, and 260, respectively. Specimens were irradiated to different fluences, including those annealed after irradiation-annealing-reirradiation cycle. The data are plotted against the unirradiated curves to observe the degree of recovery after annealing. For each material in general, the annealed data tend to group into one data set regardless of irradiation and annealing history. Among the three Charpy toughness parameters, absorbed energy appears to recover the most, lateral expansion the least, and percent shear is somewhat in between in the transition region.

On the upper-shelf, energy values of all four materials rise above the unirradiated level after annealing, similarly to results reported in Refs. $[10,13]$, while none of the materials exhibited complete recovery of lateral expansion. A limited number of unirradiated specimens of Plate 02 and Weld 502 were annealed at $454^{\circ} \mathrm{C}$. Plate 02 specimens were tested on the upper-shelf only, while Weld 502 specimens were tested over a wide temperature range. For unirradiated/annealed specimens of Plate 02 , the upper-shelf values of absorbed energy and lateral expansion are within scatter of the unirradiated values. Unirradiated/annealed specimens of Weld 502 showed slightly different behavior; the upper-shelf energy increased to the same level shown by the irradiated/annealed specimens, while lateral expansion did not change as a result of annealing.

The need for direct fracture toughness measurements is critical, especially in light of the present results where different Charpy parameters showed mixed response to annealing.

\section{Reirradiation Results}

RRC-KI also performed reirradiation of Charpy specimens of Plate 02 and Weld $73 \mathrm{~W}$ which had been irradiated and annealed at $454^{\circ} \mathrm{C}$. Moreover, some of the reirradiated specimens were subjected to additional post-reirradiation annealing at $454^{\circ} \mathrm{C}$. The data are summarized in Fig. 9. The solid line represents the embrittlement path (I) as shown earlier in Fig. 2. Specimens of both materials were initially irradiated to about $2.1 \times 10^{19} \mathrm{n} / \mathrm{cm}^{2}\left(>1 \mathrm{MeV}\right.$ ), then annealed at $454^{\circ} \mathrm{C}$ for $72 \mathrm{~h}$ (dashed line in Fig. 9). After annealing (IA), specimens were loaded back into NVNPP-5 reactor for reirradiation. The total neutron fluence was about $4.7 \times 10^{19} \mathrm{n} / \mathrm{cm}^{2}(>1 \mathrm{MeV})$ for Plate 02 and about $5.0 \times 10^{19} \mathrm{n} / \mathrm{cm}^{2}$ for Weld $73 \mathrm{~W}$. The measured shifts of transition temperature following reirradiation (IAR) were compared to those predicted by NRC Regulatory Guide 1.162 (RG 1.162) [14]. According to this guide, the reembrittlement path can be predicted by the scheme of lateral shift (dotted lines in Fig. 9). The present data show that experimentally measured shifts of transition temperature after reirradiation are well below primary embrittlement path proving benefits of annealing for RPV steels. Even the lateral shift approach provides conservative predictions of the transition temperature shifts after 


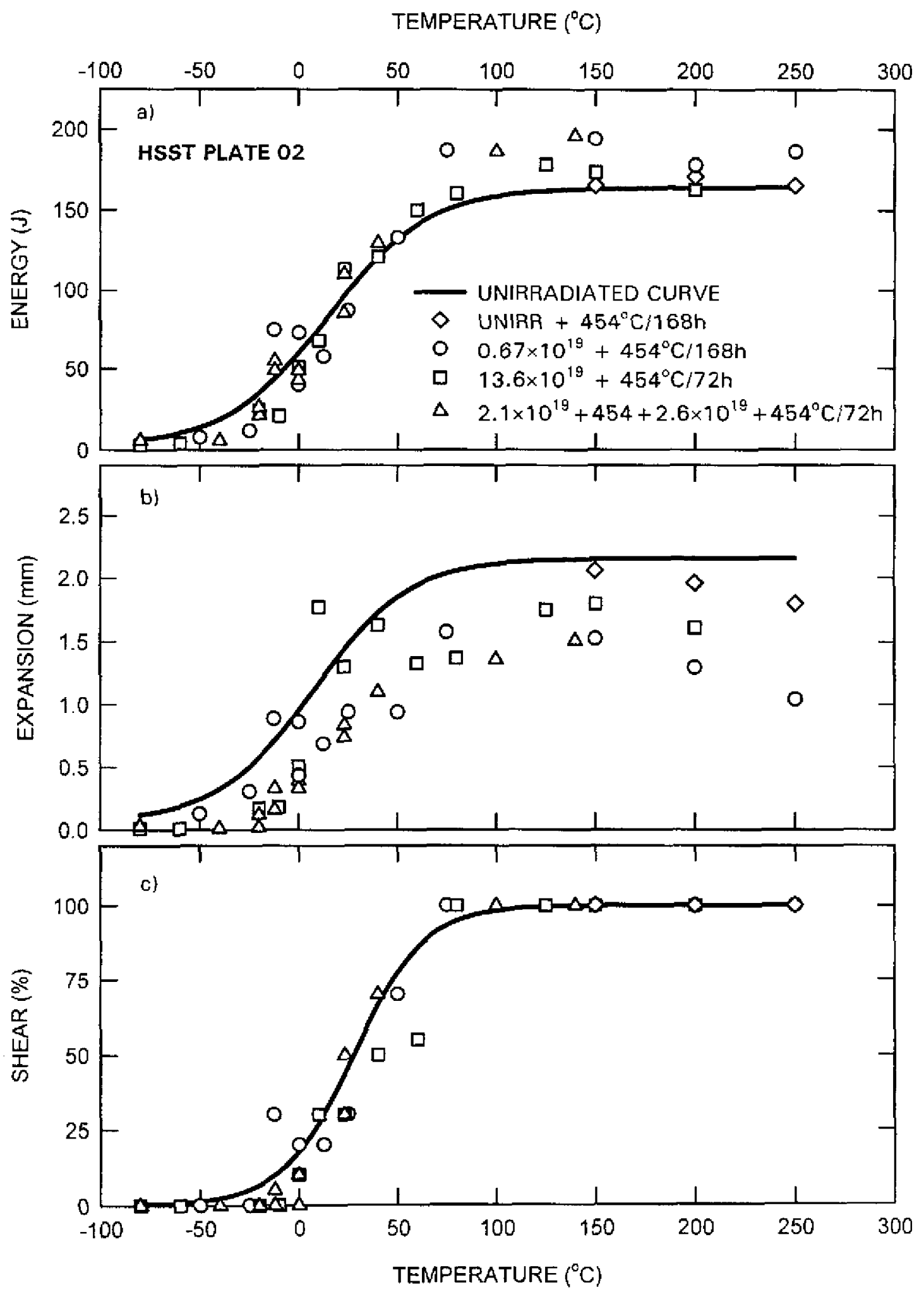

Fig. 5. Charpy data of Plate 02 in the annealed condition compared with the combined unirradiated curves. The legends in (a) apply to all three plots. 

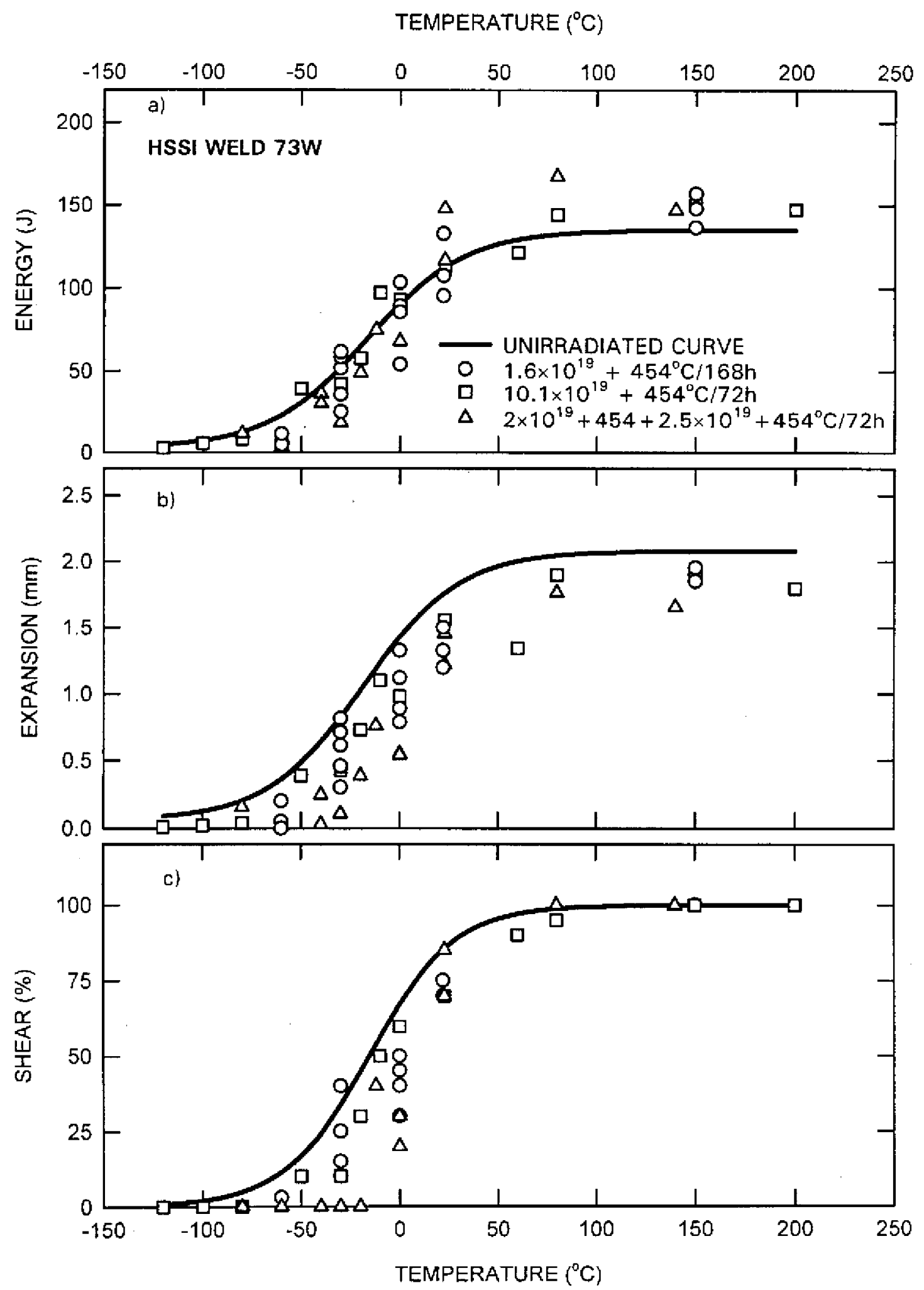

Fig. 6. Charpy data of Weld $73 \mathrm{~W}$ in the annealed conditions compared with the combined unirradiated curves. The legends in (a) apply to all three plots. 


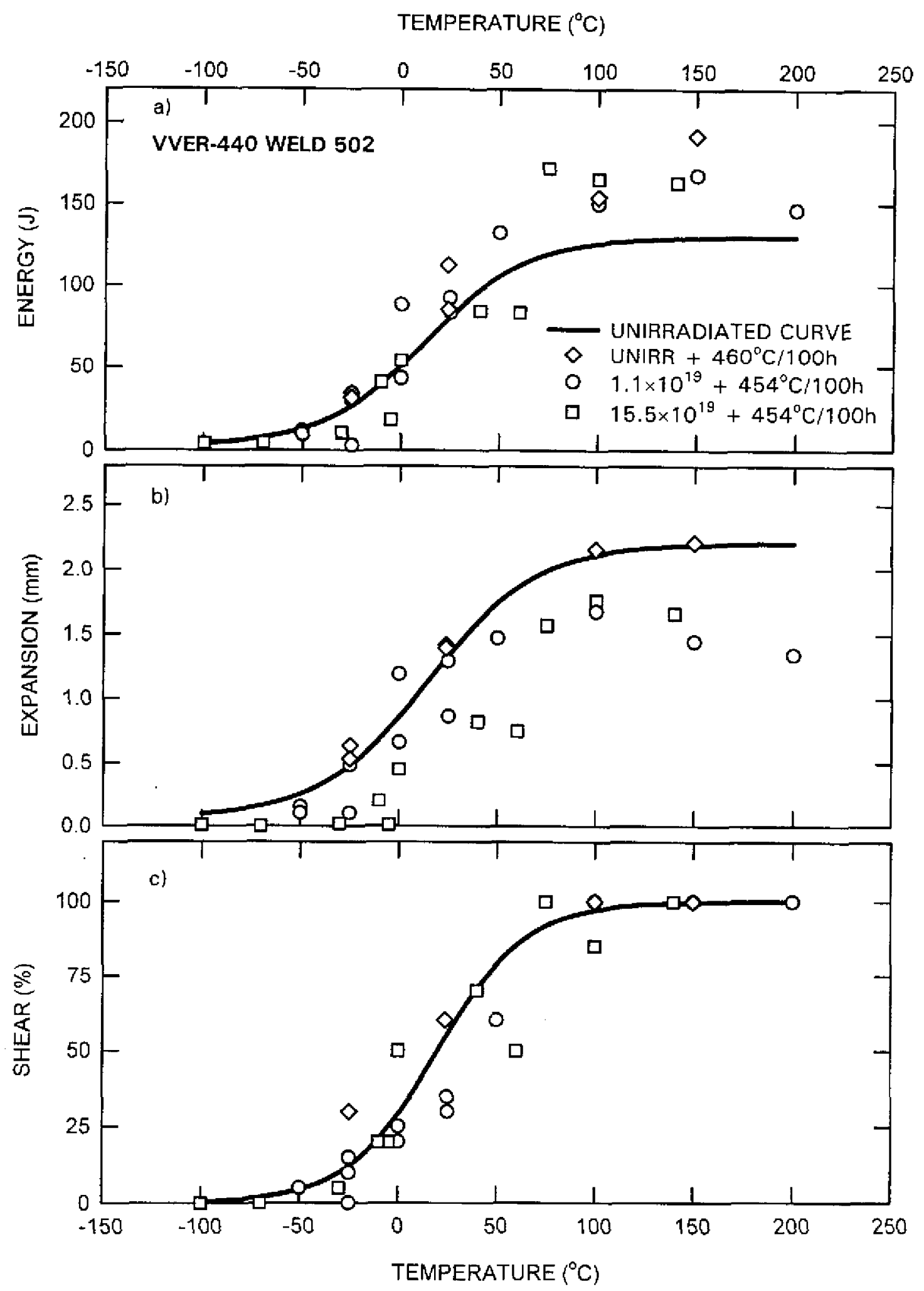

Fig. 7. Charpy data of Weld 502 in the annealed conditions compared with the combined unirradiated curves. The legends in (a) apply to all three plots. 


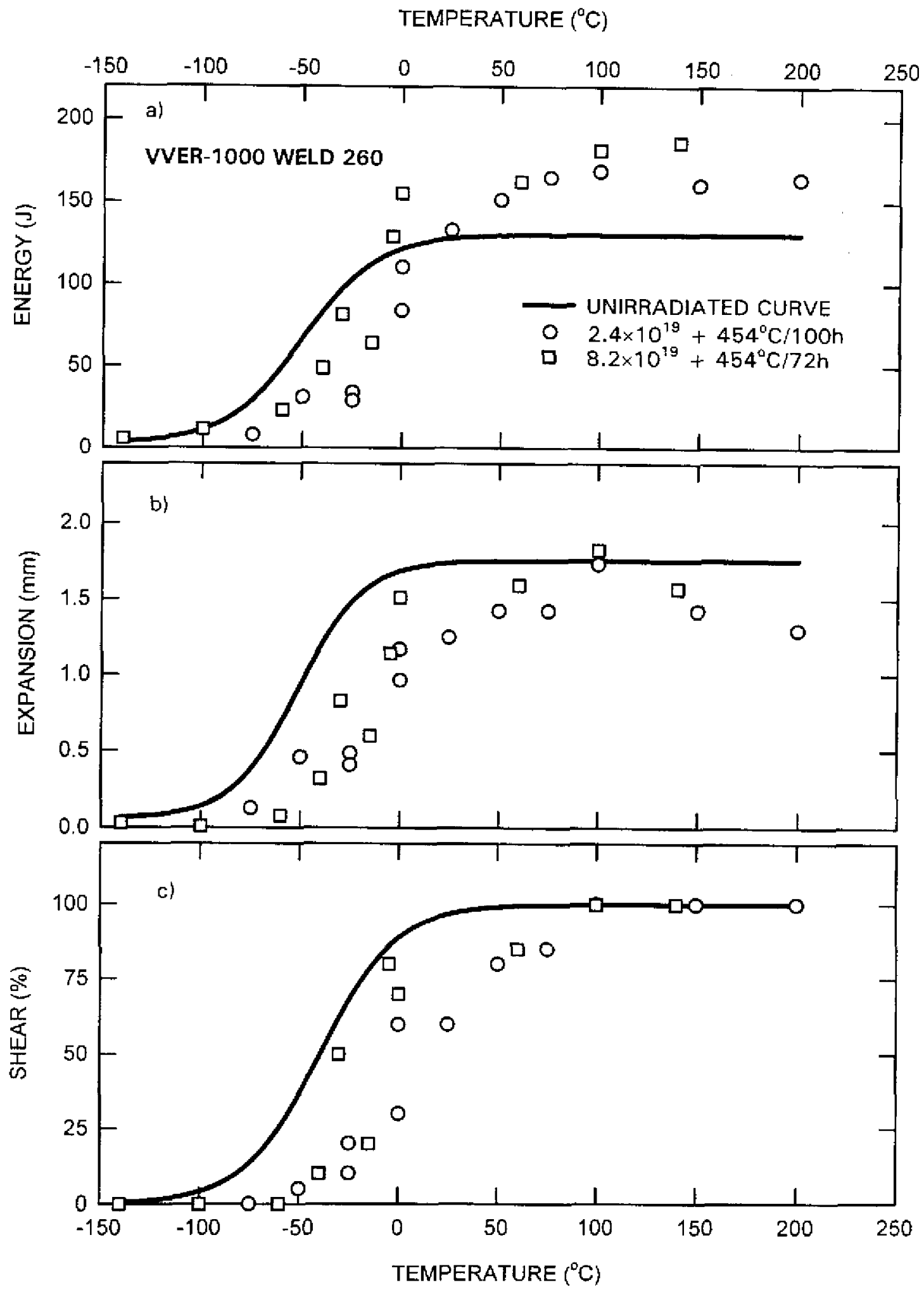

Fig. 8. Charpy data of Weld 260 in the annealed conditions compare with the combined unirradiated curves. The legends in (a) apply to all three plots. 

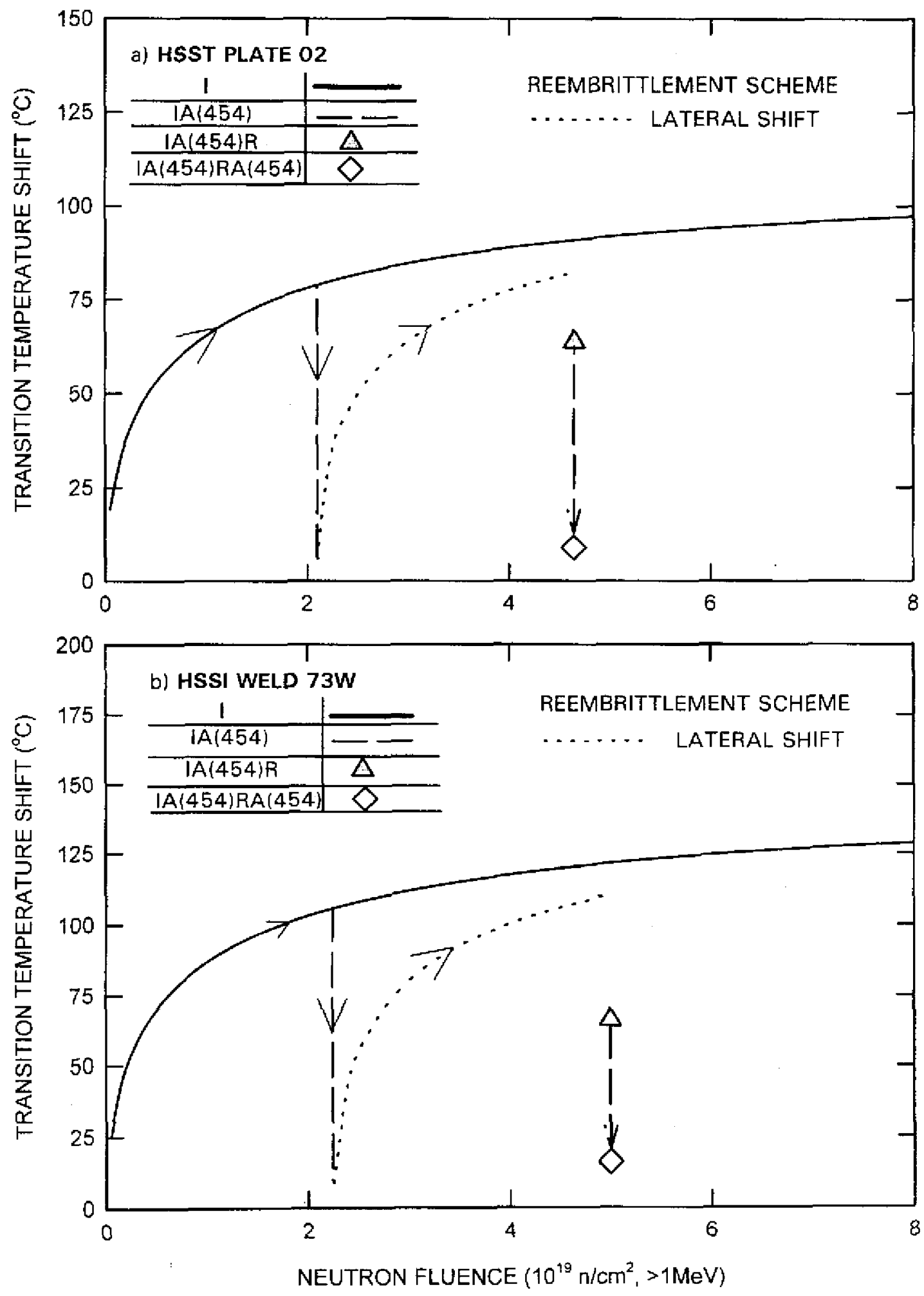

Fig. 9. Reirradiation data of (a) HSST Plate 02 and (b) HSSI Weld 73 W 
reirradiation. Reirradiation data for Weld $73 \mathrm{~W}$ are in agreement with a prediction made in Ref. [15] based on a small-angle neutron scattering (SANS) study of this weld in the irradiated and irradiated/annealed conditions. SANS measurements showed a large number of very fine copper-rich precipitates in this weld. A simple correlation between Charpy shifts and square root of volume fraction of these precipitates was shown in that study. Annealing at $454^{\circ} \mathrm{C}$ results in a significant drop of number density and volume fraction of precipitates, which corresponds well with recovery of Charpy transition temperature. However, it was found that, in addition to a decrease in number density and volume fraction, annealing results in a radius increase of these precipitates. Thus, annealing coarsens the copper-rich precipitates. As a result of these observations, it was concluded that the irradiated/annealed weld had less copper in solution that before irradiation; therefore, the reembrittlement rate of this weld should be less that it was in the primary irradiation cycle. From a radiation sensitivity point of view, the irradiated/annealed weld is microstructurally different than it was before irradiation. The present results support these conclusions. Annealing of the reirradiated materials showed the same degree of transition temperature recoveries as those achieved for the first annealings [16].

\section{Observations and Conclusions}

1. Two U.S. steels, one plate of A 533 grade B class 1 and one submerged-arc weld (with Linde 0124 flux), and two Russian welds, one representative of older VVER-440 RPVs and the other representative of older VVER-1000 RPVs, were irradiated at a wide range of neutron fluences. All four materials were annealed following irradiation, while the U.S. steels were also reirradiated and annealed following reirradiation. The experiments with the U.S. steels were conducted in Russia and those for the Russian steels in the United States.

2. The ORNL and RRC-KI experiments showed generally good agreement for both the Russian and U.S. steels.

3. While transition temperature recovery following annealing of the Charpy $41-\mathrm{J}$ transition temperature was substantial in all cases, significantly less recovery of the Charpy lateral expansion and percent shear fracture were observed. On the upper shelf, energy values of all four materials recovered to values above those of the unirradiated condition, while none of the materials exhibited complete recovery of lateral expansion.

4. Neither HSST Plate nor HSSI Weld 73W exhibited unexpected radiation sensitivity at very high neutron fluences; i.e., greater than $1 \times 10^{20} \mathrm{n} / \mathrm{cm}^{2}(>1 \mathrm{MeV})$; furthermore, both highly irradiated materials exhibit nearly full recovery of $\mathrm{CVN}$ transition temperature after thermal annealing at $454^{\circ} \mathrm{C}$.

5. The reirradiation embrittlement rates for both HSST Plate 02 and HSSI Weld $73 \mathrm{~W}$ are conservative relative to the "lateral shift" method for reembrittlement prediction. 


\section{Acknowledgments}

This research is sponsored by the Division of Engineering Technology, Office of Nuclear Regulatory Research, U.S. Nuclear Regulatory Commission, under Interagency Agreement DOE 1886-N695-3W with the U.S. Department of Energy under Contract DE-AC05-960R22464 with Lockheed Martin Energy Research Corporation.

\section{References}

[1] W. J. Stelzman, R. G. Berggren, and T. N. Jones, Jr., ORNL Characterization of Heavy-Section Steel Technology Program Plates 01,02, and 03, NUREG/CR-4092 (ORNL/TM-9491), Oak Ridge National Laboratory, Oak Ridge, Tenn., 1985.

[2] R. K. Nanstad, F. M. Haggag, D. E. McCabe, S. K. Iskander, K. O. Bowman, and B. H. Menke, Irradiation Effects on Fracture Toughness of Two High-Copper Submerged-Arc Welds, HSSI Series 5, NUREG/CR-5913, Vol. 1 (ORNL/TM-12156/V1), Oak Ridge National Laboratory, Oak Ridge, Tenn, 1992.

[3] R. K. Nanstad, D. E. McCabe, B. H. Menke, S. K. Iskander, and F. M. Haggag, "Effects of Radiation on $\mathrm{K}_{\mathrm{Ic}}$ Curves for High Copper Welds," pp. 214-233 in Effects of Radiation on Materials: 14th International Symposium, ASTM STP 1046, N. H. Packan, R. E. Stoller, and A. S. Kumar, Eds., American Society for Testing and Materials, Philadelphia, 1990.

[4] R. K. Nanstad and M. A. Sokolov, "Charpy Impact Test Results on Five Materials and NIST Verification Specimens Using Instrumented 2-mm and 8-mm Strikers," pp. 111-139 in Pendulum Impact Machines: Procedures and Specimens for Verification, ASTM STP 1248, T. A. Siewert and A. K. Schmieder, Eds,, American Society for Testing and Materials, Philadelphia, 1995.

[5] R. G. Berggren, J. R. Hawthorne, and R. K. Nanstad, "Analysis of Charpy V-Notch Impact Toughness of Irradiated A533-B Class 1 Plate and Four Submerged-Arc Welds," pp. 1094-1110 in Effects of Radiation on Materials: 12th International Symposium, ASTM STP 870, F, A. Garner and J. S. Perrin, Eds., American Society for Testing and Materials, Philadelphia, 1985.

[6] B. H. Menke, J. J. McGowan, R. G. Berggren, R. K. Nanstad, and K. C. Miller, "Effects of Neutron Irradiation on Fracture Toughness of A533-B Class 1 Plate and Four Submerged-Arc Welds," pp. 1111-1130 in Effects of Radiation on Materials: 12th International Symposium, ASTM STP 870, F. A. Garner and J. S. Perrin, Eds., American Society for Testing and Materials, Philadelphia, 1985.

[7] M. A. Sokolov and D. E. McCabe, Comparison of Irradiation-Induced Shifts of $K_{J_{c}}$ and Charpy Curves: Analysis of Heavy-Section Steel Irradiation Program Data, ORNL/NRC/LTR-95/4, Oak Ridge National Laboratory, Oak Ridge, Tenn., 1995.

[8] Regulatory Guide 1.99, "Radiation Embrittlement of Reactor Vessel Materials," Revision 2, U.S. Nuclear Regulatory Commission, Washington, D.C., May 1988.

[9] Calculation Standards for Strength of Equipment and Pipes of Nuclear Power Units, PNAE-G-002-86, Energoatomizdat, NGA-01-85-1, NIKIET (in Russian), 1989. 
[10] M. A. Sokolov, D. E. McCabe, S. K. Iskander, and R. K. Nanstad, "Comparison of Fracture Toughness and Charpy Impact Properties Recovery by Thermal Annealing of Irradiated Reactor Pressure Vessel Steels," pp. 771-781 in 7th International Symposium on Environmental Degradation of Materials in Nuclear Power Systems - Water Reactors, Vol. 2, American Nuclear Society, La Grange Park, Ill,, 1995.

[11] M. A. Sokolov and R. K. Nanstad, "Comparison of Irradiation-Induced Shifts of $\mathrm{K}_{\mathrm{Jc}}$ and Charpy Impact Toughness for Reactor Pressure Vessel Steels," pp. 167-190 in Effects of Radiation on Materials, I8th International Symposium, ASTM STP 1325, R. K. Nanstad, M. L. Hamilton, F. A. Garner, and A. S. Kumar, Eds., American Society for Testing and Materials, West Conshohocken, Pa., 1999.

[12] A. D. Amayev, A. M. Kryukov, and M. A. Sokolov, "Recovery of the Transition Temperature of Irradiated WWER-440 Vessel Metal by Annealing," pp. 369-379 in Radiation Embrittlement of Nuclear Reactor Pressure Vessel Steels: An International Review (Fourth Volume), ASTM STP 1170, L. E. Steele, Ed., American Society for Testing and Materials, Philadelphia, 1993.

[13] S. K. Iskander, M. A. Sokolov, and R. K. Nanstad, "Effects of Annealing Time on the Recovery of Charpy V-Notch Properties of Irradiated High-Copper Weld Metal," pp. 277-293 in Effects of Radiation on Materials: 17th International Symposium, ASTM STP 1270, D. S. Gelles, R. K. Nanstad, A. S. Kumar, and E. A. Little, Eds., American Society for Testing and Materials, Philadelphia, 1996.

[14] Regulatory Guide 1.162, "Format and Content of Report for Thermal Annealing of Reactor Pressure Vessels," U.S. Nuclear Regulatory Commission, February 1996.

[15] M. A. Sokolov, S. Spooner, G. R. Odette, B. D. Wirth, and G. E. Lucas, "SANS Study of High-Copper RPV Welds in Irradiated and Annealed Conditions," pp. 333-345 in Effects of Radiation on Materials, 18th International Symposium, ASTM STP 1325, R. K. Nanstad, M. L. Hamilton, F. A. Garner, and A. S. Kumar, Eds., American Society for Testing and Materials, West Conshohocken, Pa., 1999.

[16] A. A. Chernobaeva, M. A. Sokolov, R. K. Nanstad, A. M. Kryukov, Y. A. Nikolaev, and Yu. N. Korolev, "Exploratory Study of Irradiation, Annealing, and Reirradiation Effects on American and Russian Reactor Pressure Vessel Steels," pp. 871-882 in Proceedings of the Eighth International Symposium on Environmental Degradation of Materials in Nuclear Power Systems - Water Reactors, August 10-14, 1997, Amelia Island, Florida, American Nuclear Society, La Grange Park, Ill., 1997. 